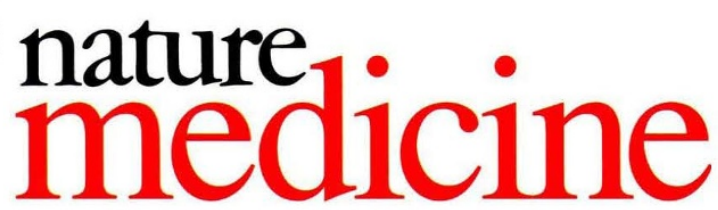

VOLUME 3 • NUMBER 1 • JANUARY 1997

\title{
The microbial plague continues
}

A photograph in a recent issue of the Washington Post shows a rugged young man who was a competitor in the recent Ironman triathlon in Hawaii. It is an advertisement from "America's Pharmaceutical Research Companies," claiming a victory over AIDS. Thanks to the newly developed "cocktail" of anti-AIDS drugs, including protease inhibitors, a young man with AIDS competed in a triathlon, beating the odds against death.

Although we have been editorially optimistic (Nature Medicine 2, 253; 1996), during the ensuing months, accumulated enthusiasm about protease inhibitors and related AIDS advances has grown out of proportion. Research published in Nature Medicine, Nature and other peer-reviewed journals has been made much of by major newspapers and news magazines with worldwide distribution. AIDS stories are splashed across the covers of Newsweek and Time. Even the 10 November New York Times Sunday magazine's cover story was titled, "When Plagues End: Notes on the Twilight of an Epidemic."

If only it were true. Last month in these pages, M. Patricia D'Souza, a virologist, and Victoria A. Harden, a historian, wrote a compelling review of the progress that has taken place in AIDS research during the past year. Their article, "Chemokines and HIV-1 Second Receptors," (Nature Medicine 2, 1293$1300 ; 1996)$ is a wonderful, classic story of how science works when things go right-when an insight in one laboratory into the fundamental biology of a microbe leads others to join in rapid, successful pursuit of an idea from bench to bedside. But they describe a battle - not the end of the war.

No one denies the fact that for most wealthy or well-insured AIDS patients in Western countries AIDS has, within
12 months' time, been transformed from a fatal to a chronic, treatable disease, at least for the time being. But no one should jump to the conclusion that the human mind and pharmaceutical ingenuity have gotten the best of the human immunodeficiency virus - HIV.

\section{SOME BATTLES HAVE BEen WON,}

\section{BUT THE WAR IS NOT OVER.}

The new "cocktail" treatment, which can cost as much as $\$ 15,000$ a year, succeeds only when the patient follows a strict regimen of drug-taking that requires intelligence, diligence and the help of a good doctor. Even then, 15 percent of HIV-infected patients who get the drugs are not helped by them. Worse yet, a patient who misses even a dose or two may be setting himself up for drug resistance, because HIV is quick to mutate in ways that evade the cocktail of anti-HIV agents. Therefore, physicians face a real dilemma in deciding whether to treat those patients who are down and out, who lack the discipline or ability to follow a complex pill-taking regimen. The great fear of some clinicians and researchers in the midst of the good news is that selective pressure for resistant strains in those who take the drugs haphazardly will create a mutant HIV resistant to even the new drugs. That new mutant (if it does arise) could then spread unchecked through the most vulnerable populations, rendering even the new "miracle" drugs worthless. It is clear that prevention of HIV infection is still preferable to treating after infection.

AIDS, of course, is not our only micro- bial challenge. As evidenced in this issue of Nature Medicine, malaria still lurks among us. In fact, it threatens the health and lives of 2400 million people worldwide. As Marlie MacLean and her colleagues write in a Commentary (pp. 14-16) "In the time it takes you to read this article 23 people will have died of malaria." While the Commentary spells out a course of expensive research that is all too likely to be ignored by funding agencies in those nations that have the money to do this research, S.L. Hoffman and his colleagues describe only a few pages later (pp. 80-83) exciting new data on the use of interleukin-12 as a potential vaccine against malaria. The news is good, but no one should be fooled into believing that the end of malaria is in sight.

And finally, in the microbe war, comes this report from the 7 December issue of the Lancet. Two patients admitted to St. George's Hospital in London were infected with a strain of Enterococcus faecium that is not only resistant to vancomycin but that actually requires the antibiotic in order to reproduce. I suppose it should not come as a surprise-a bacteria that depends on antibiotics for its very life. The authors write that dependence on vancomycin renders the $E$. faecium mutant "not only resistant to treatment but also undetectable unless it is specifically looked for ...." And, they ask, "Have we at last witnessed the emergence of a true superbug?"

A year ago, Nature Medicine published a report from scientists in India about the recurrence of plague in the subcontinent $(1$, $1237-1239 ; 1995)$, and stated in an editorial that, when it comes to human health, the emergence and reemergence of oncetamed microbes constitutes "the greatest threat of all." Nothing has changed. - Barbara J. Culliton 